\title{
Inactivation of the Olfactory Marker Protein $(O M P)$ Gene in River Dolphins and other Odontocete Cetaceans
}

\author{
Mark S. Springer ${ }^{1}$, John Gatesy ${ }^{2}$ \\ ${ }^{1}$ Department of Biology, University of California, Riverside, CA 92521, USA \\ ${ }^{2}$ Division of Vertebrate Zoology, American Museum of Natural History, New York, NY \\ 10024, USA
}

E-mail: mark.springer@ucr.edu (MSS); jgatesy@amnh.org (JG)

Keywords: anosmia, Cetacea, echolocation, Odontoceti, olfaction, olfactory marker protein

\begin{abstract}
Various toothed whales (Odontoceti) are unique among mammals in lacking olfactory bulbs as adults and are thought to be anosmic (lacking the olfactory sense). At the molecular level, toothed whales have high percentages of pseudogenic olfactory receptor genes, but species that have been investigated to date retain an intact copy of the olfactory marker protein gene $(O M P)$, which is highly expressed in olfactory receptor neurons and may regulate the temporal resolution of olfactory responses. One hypothesis for the retention of intact $O M P$ in diverse odontocete lineages is that this gene is pleiotropic with additional functions that are unrelated to olfaction. Recent expression studies provide some support for this hypothesis. Here, we report $O M P$ sequences for representatives of all extant cetacean families and provide the first molecular evidence for inactivation of this gene in vertebrates. Specifically, $O M P$ exhibits independent inactivating mutations in six different odontocete lineages: four river dolphin genera (Platanista, Lipotes, Pontoporia, Inia), sperm whale (Physeter), and harbor porpoise (Phocoena). These results suggest that the only essential role of $O M P$ that is maintained by natural selection is in olfaction, although a non-olfactory role for $O M P$ cannot be


ruled out for lineages that retain an intact copy of this gene. Available genome sequences from cetaceans and close outgroups provide evidence of inactivating mutations in two additional genes (CNGA2, CNGA4), which imply further pseudogenization events in the olfactory cascade of odontocetes. Selection analyses demonstrate that evolutionary constraints on all three genes (OMP, CNGA2, CNGA4) have been greatly reduced in Odontoceti, but retain a signature of purifying selection on the stem Cetacea branch and in Mysticeti (baleen whales). This pattern is compatible with the 'echolocation-priority' hypothesis for the evolution of $O M P$, which posits that negative selection was maintained in the common ancestor of Cetacea and was not relaxed significantly until the evolution of echolocation in Odontoceti.

\section{Introduction}

Among living mammals, toothed whales (Odontoceti) are unique in having lost the sense of smell (=anosmia), presumably because detection of airborne odorants was rendered obsolete with the evolution of underwater echolocation for detection of prey, social communication, predator avoidance, and navigation in low light conditions (Cave, 1988; Hoch, 2000; Godfrey, 2013; Berta et al., 2014). Toothed whales, along with other living cetaceans $($ Mysticeti = baleen whales), have also lost the vomeronasal organ $($ Flower, 1883; Oelschläger et al., 1987; Bajpai et al., 2011; Kishida et al., 2015), which is closely affiliated with olfaction and detects pheromones (Keverne, 1999). At the morphological level, adult odontocetes that have been examined lack the olfactory nerve, bulb, and tract, and these structures only appear transiently during development (Flower, 1883; Slijper, 1962; Oelschläger, 1992, 2008; Thewissen et al., 2010). Extant odontocetes also lack osteological correlates of olfaction including endoturbinals, which support olfactory epithelium, and the cribriform plate of the ethmoid, which possesses foramina that transmit branches of the olfactory nerve (cranial nerve I). This overall condition, which is generally thought to have evolved in the common ancestor of extant odontocetes (Heyning, 1997; Gatesy et al., 2013), contrasts with the reduced, but presumably functional, olfactory anatomy observed in various mysticete species (Flower, 1883; Cave, 
1988; Thewissen et al., 2010; Godfrey et al., 2013) and the presence of endoturbinals and a cribriform plate in stem cetaceans (Bianucci and Gingerich, 2011; Godfrey et al., 2013).

Some extinct odontocetes from the Oligocene and Miocene do retain osteological proxies of a functional sense of smell (Fordyce, 1994; Hoch 2000; Godfrey 2013), but it remains unclear whether particular fossils are nested within crown Odontoceti or represent branches of the odontocete stem lineage (Fordyce, 1994; Geisler and Sanders, 2003; Geisler et al., 2011). For example, Hoch (2000) suggested platanistoid affinities for an unnamed late Oligocene fossil with osteological features linked to a functional sense of smell. This hypothesis posits a close relationship to the extant river dolphin Platanista and implies retention of olfactory structures in the last common ancestor of extant odontocetes, with multiple independent losses of these structures within crown Odontoceti (Gatesy et al., 2013). If the fossil is instead a stem odontocete, a single loss of olfactory structures in Odontoceti, the traditional interpretation (e.g., Heyning, 1997), is a viable alternative hypothesis.

At the molecular level, the genomes of toothed whales also show definitive evidence for degradation of the olfactory sense. Odontocetes have a greatly reduced set of intact olfactory receptor (OR) genes relative to terrestrial mammals. Instead, odontocete genomes are riddled with defunct OR pseudogenes (Kishida et al., 2007, 2015; McGowen et al. 2008; Hayden et al. 2010; Zhou et al., 2013). In addition, multiple olfactory-related genes (OMACS, NQO1) and most members of the trace amineassociated receptor (TAAR) gene family have been inactivated in the common ancestor of Cetacea (Kishida et al., 2015). However, to our knowledge, there are no published reports of single-copy genes in the olfactory signal transduction cascade that are inactivated in anosmic toothed whales but remain functional in baleen whales.

Olfactory marker protein $(O M P)$ is a single-copy intronless gene that is highly expressed in the olfactory epithelium of mammals (Danciger et al., 1989), but OMP is intact and lacks clear-cut inactivating mutations in odontocete species that have been investigated to date (Kishida and Thewissen, 2012). Knockout experiments in mice (Buiakova et al., 1996) suggest that OMP plays an important role in olfactory signal transduction, where it may regulate the kinetics and termination of olfactory responses, facilitating the temporal resolution of odor stimulus (Reisert et al., 2007). It has also been 
suggested that OMP plays a role in the developmental wiring of olfactory axons. OMP is not present in the early stages of olfactory neurogenesis, when individual neurons may express multiple ORs, but is detected later in mature olfactory neurons that express just one OR gene (Tan et al., 2015; Abdus-Saboor et al., 2016). Aside from OR neurons, OMP also occurs in the central nervous system (Baker et al., 1989; Kishida and Thewissen, 2012) and could contribute to OR-mediated chemoreception in a variety of non-olfactory tissues in mouse (Kang et al., 2015). Pleiotropy therefore provides one explanation for the retention of intact $O M P$ coding sequences in anosmic odontocetes (Kishida and Thewissen, 2012).

Kishida and Thewissen (2012) outlined two scenarios, the 'filter-feeder' hypothesis and the 'echolocation-priority' hypothesis, that describe changes in the importance of olfaction in cetacean evolutionary history and related these hypotheses to the predicted molecular evolution of $O M P$. The filter-feeder hypothesis posits relaxed stabilizing selection on the olfactory sense on the stem Cetacea branch in conjunction with the sequential evolution of various aquatic specializations. Relaxed selection on $O M P$ was maintained in odontocetes according to this hypothesis, but strong purifying selection on $O M P$ was restored in mysticetes that may utilize olfaction to locate planktonic prey (Fig. 1A). By contrast, the echolocation-priority hypothesis posits that strong purifying selection on $O M P$ was maintained in the common ancestor of Cetacea and was not relaxed until the evolution of echolocation on the stem of Odontoceti (Fig. 1B).

Based on $\mathrm{dN} / \mathrm{dS}(=\omega)$ analyses of $O M P$ data, where $\mathrm{dN}$ is the nonsynonymous substitution rate and $\mathrm{dS}$ is the synonymous substitution rate, Kishida and Thewissen (2012) showed that there is more support for the filter-feeder hypothesis (Fig. 1A). They inferred an extreme relaxation of ancestral selective constraints on what they termed the "Eocene whale branch" that extends from the common ancestor of Cetruminantia $($ Cetacea + Hippopotamidae + Ruminantia) to the common ancestor of extant cetaceans (a representative hippopotamid was not sampled). Relaxed selective constraints on $O M P$ were maintained in Odontoceti $(\omega=0.53)$, but the $\omega$ value of mysticete branches $(0.06)$ suggests a return to the strongly negative selection recorded in outgroups to Cetacea $(\omega=$ $0.05)$. 
For Odontoceti, the relatively high $\omega$ value, as well as in-frame deletions in domains of $O M P$ that generally lack such mutations across Mammalia, suggest that inactivating mutations in $O M P$ might be found in anosmic toothed whales that were not sampled previously (Kishida and Thewissen, 2010). The absence of such mutations in odontocete species that have been characterized to date could simply represent lags in mutational evidence for inactivation of $O M P$. For example, if loss of olfaction on the stem odontocete branch released all functional constraints on $O M P$, the gene would subsequently have evolved in a completely neutral manner, but some time might pass before frameshift mutations evolved in one or more lineages (Fig. 1C). Alternatively, the discovery of inactivating mutations in previously unsampled odontocete lineages might provide molecular evidence for parallel loss of olfaction within crown Odontoceti (McGowen et al., 2008), depending on the pattern of $\omega$ values on different branches within this clade (Fig. 1D).

Here, we report complete coding sequences for $O M P$ that, in combination with published data, represent all living families of Cetacea. Characterization of inactivating mutations (frameshifts, premature stops, altered start codons, stop codons, and splice sites) in these sequences as well as estimates of selection intensity enable a test of the hypothesis that $O M P$ is pleiotropic and has essential functions beyond olfaction in anosmic odontocetes. Our expanded data set of $O M P$ sequences, which includes a representative hippopotamid that subdivides Kishida and Thewissen's (2012) "Eocene whale" branch, also provides an opportunity to re-examine the filter-feeder and echolocation-priority hypotheses that predict alternative patterns of selective constraints on $O M P$ in Cetacea (Fig. 1). Given evidence for inactivation of $O M P$ in some odontocete lineages, we also report analyses of two additional genes with putative olfactory-specific functions, cyclic nucleotide-gated channel alpha 2 (CNGA2) and cyclic nucleotide-gated channel alpha 4 (CNGA4). These loci encode subunits of the olfactory cyclic nucleotidegated $(\mathrm{CNG})$ channel that is critical for depolarizing OR neurons and initiating action potentials that are sent to the brain (Michalakis et al., 2006; Nache et al., 2016). Olfactory CNG channels are heterotetramers that are comprised of two CNGA2 subunits, one CNGA4 subunit, and one CNGB1b unit. However, unlike CNGA2 and CNGA4, both of which are thought to be olfactory-specific, CNGB1b is a component of CNG channels in 
both visual (rod-based) and olfactory transduction cascades (Michalakis et al., 2006) and is not expected to be inactivated in conjunction with anosmia. We use data from published genomes to test whether $C N G A 2$ and $C N G A 4$ are pseudogenized in different subclades of Cetacea.

\section{Methods}

\subsection{Database mining and BLAST searches.}

Nucleotide megaBLAST searches (http://blast.ncbi.nlm.nih.gov/Blast.cgi) were performed using $O M P$ coding sequences from mRNAs, some of which were predicted by NCBI's Gnomon software, as query sequences against NCBI's whole-genome shotgun contigs. We targeted all placental mammals with genome sequences in this database. We used query sequences from representatives of each placental order to BLAST the genomes of all taxa from the same order (e.g., Canis lupus OMP was used to BLAST the genomes of carnivorans). For each genome that was BLASTed, we only considered the top BLAST hit except in cases where the complete $O M P$ gene was not included in a single contig (Daubentonia madagascariensis, Nomascus leucogenys, Okapia johnstoni). $O M P$ coding sequences and $\sim 200 \mathrm{bp}$ of flanking sequence on each end of the coding region were downloaded and imported into Geneious 9.1.5 (Kearse et al., 2012). We also blasted the sequence read archive (SRA) for Balaenoptera physalus (fin whale) (Yim et al., 2014) and Odobenus rosmarus (walrus) (Foote et al., 2015) with query sequences from Balaenoptera acutorostrata (common minke whale) and Leptonychotes weddellii (Weddell seal), respectively. BLAST hits from these searches were downloaded and assembled in Geneious. Finally, we imported the genome of Balaena mysticetus (bowhead whale) (Keane et al., 2015) into Geneious and queried this genome with the discontiguous megablast option. In addition to DNA sequences extracted from published genomes, cetacean $O M P$ data generated by PCR amplification and Sanger sequencing (Kishida and Thewissen, 2012) were downloaded from GenBank (4 odontocetes, 1 mysticete). In addition to $O M P$, we also employed the above-described strategy to target two CNG protein subunits, $C N G A 2$ and $C N G A 4$, for seven cetaceans with assembled 
genomes (Balaena mysticetus, Balaenoptera acutorostrata, Balaenoptera bonaerensis [Antarctic minke whale], Physeter macrocephalus [sperm whale], Lipotes vexillifer [Yangtze River dolphin], Tursiops truncatus [bottlenose dolphin], Orcinus orca [killer whale]) and 12 cetartiodactyl and perissodactyl outgroups.

\subsection{PCR and Sanger sequencing}

In their initial PCR survey of $O M P$, Kishida and Thewissen (2012) sampled five of the 14 extant families of Cetacea. We extended this work by sampling a representative of Hippopotamidae, the extant sister-group of whales (Gatesy et al., 2013), and 16 additional species from ten families of Cetacea. These sequences combine with published data to cover most major extant lineages of the clade (Supplementary Table S1). The entire coding sequence of $O M P$ and short stretches of flanking regions were PCR amplified using the following forward $(\mathrm{F})$ and reverse $(\mathrm{R})$ primers (5' to $3^{\prime}$ '):

\section{OMP_F3, AGTCCACTCGGCTCCTGGACGGTGGAGGCGGCAG}

\section{OMP_R3, AGCCAAGTACAGGCCAGCAGCTAGAAGAATGTCC}

PCR reactions were performed in $50 \mu \mathrm{l}$ volumes and contained $67 \mathrm{mM}$ Tris, $3 \mathrm{mM}$ $\mathrm{MgCl}_{2}, 16.6 \mathrm{mM}\left(\mathrm{NH}_{4}\right)_{2} \mathrm{SO}_{4}, 200 \mu \mathrm{M}$ dNTPs, $1 \mu \mathrm{M}$ of each primer, and $1 \mathrm{U}$ of $\mathrm{Taq}$ polymerase (Invitrogen). Amplifications included an initial 2 min denaturation phase (94 C); followed by 45 cycles with 1 min denaturation $\left(94^{\circ} \mathrm{C}\right), 1$ min annealing $\left(60^{\circ}-66^{\circ} \mathrm{C}\right)$, 1 min extension $\left(72^{\circ} \mathrm{C}\right)$; and a final 2 min elongation phase $\left(72^{\circ} \mathrm{C}\right)$. PCR products were cleaned and concentrated using Montage PCR Centrifugal Filter Devices (Millipore) and then Sanger sequenced in both directions using the above PCR primers. GenBank accession numbers for new OMP sequences are KY496975-KY496991.

\subsection{Alignments and phylogenetic analyses}

Sequences were aligned using MAFFT (Katoh et al., 2002) in Geneious with 
minor modifications by eye. Phylogenetic analyses were performed with RAxML 8.2.8 (Stamatakis, 2006) on CIPRES (Miller et al., 2010) using a GTR $+\Gamma$ model of sequence evolution for both individual bootstrap pseudoreplicates and the search for the highest likelihood tree. Rapid bootstrapping (Stamatakis et al., 2008) was performed with 500 pseudoreplicates. Bootstrapping and a search for the best ML tree were performed in a single run.

\subsection{Inactivating mutations}

$O M P$ sequences from 133 mammalian species were inspected for inactivating mutations (altered start codons, frameshift insertions and deletions, premature stop codons, changes at splice sites, and altered stop codons) using Geneious. The alignment of 133 taxa is posted online (Supplementary Alignment File 1). We also inspected $C N G A 2$ and CNGA4 sequences for inactivating mutations (Supplementary Alignment Files 2, 3). Parsimony optimizations with delayed transformation (deltran) were performed with PAUP* 4.0a150 (Swofford, 2002) to map mutations to particular branches in the phylogeny of Cetartiodactyla.

\subsection{Selection analyses}

Branch analyses that estimated the ratio $(\omega=\mathrm{dN} / \mathrm{dS})$ of the nonsynonymous substitution rate $(\mathrm{dN})$ to the synonymous substitution rate $(\mathrm{dS})$ were performed with the codeml program in PAML 4.8 (Yang, 2007). For OMP, analyses were performed with a subset of sequences from Supplementary Alignment File 1 that included 28 cetaceans and 22 outgroups as follows: 17 odontocetes, 11 mysticetes, 12 non-cetacean cetioartiodactyls, seven carnivorans, two perissodactyls, and one pholidotan (Supplementary Alignment File 4). Frameshift insertions were deleted prior to codeml analyses. Akaike Information Criterion (AIC) scores were used to select the most appropriate codon frequency model in codeml (Table 1). Given that the OMP gene tree exhibits numerous topological relationships that are unrelated to incomplete lineage sorting (see Results), we used a species tree with relationships supported by published 
multigene studies. Interordinal and interfamilial relationships followed Meredith et al. (2011a). Additional relationships follow Gatesy et al. (2013) for Cetacea, Hassanin et al. (2012) for terrestrial cetartiodactyls, and Johnson et al. (2006) for felids.

Branch analyses for $O M P$ were performed with seven different selection models to test competing hypotheses pertaining to the evolution of $O M P$ in different parts of the cetacean tree relative to non-cetaceans (Fig. 2A-G). Model 1 permits just one $\omega$ value for all branches. Model 2 has two $\omega$ categories and corresponds to the echolocation-priority hypothesis (Kishida and Thewissen, 2012) in which relaxed selection on OMP in Odontoceti commenced with the evolution of echolocation on the stem odontocete branch (Fig. 1B). Model 3 has three $\omega$ categories and approximately corresponds to Kishida and Thewissen's (2012) filter-feeder hypothesis (Fig. 1A), according to which selection initially was relaxed on the "Eocene whale" branch where the transition to marine environments occurred (Uhen, 2010; Gatesy et al., 2013; Berta et al., 2014). The three categories for Model 3 correspond to non-cetacean branches, stem Cetacea plus all odontocete branches, and stem plus crown Mysticeti (Fig. 2C). Model 4 has four $\omega$ categories and is another variant of Kishida and Thewissen's (2012) filter-feeder hypothesis. Instead of a single $\omega$ for the stem Cetacea plus odontocete branches, Model 4 allows for separate $\omega$ categories on the stem Cetacea branch versus odontocete branches, given evidence for OMP inactivation in some odontocetes. Models 5-7 represent variations of the echolocation- priority hypothesis (Model 2). There are three $\omega$ categories in Model 5, where odontocete branches with inactivating mutations are allowed to have a different $\omega$ value than odontocete branches without inactivating mutations (Fig. 2D). This model tests the hypothesis that branches with inactivating mutations have a higher $\omega$ value than branches without inactivating branches because the former have transitioned from functional to pseudogenic as evidenced by the presence of inactivating mutations, whereas the latter may remain under purifying selection (Fig. 1D). Model 6 has two $\omega$ categories and enforces $\omega=1.0$ on stem and crown odontocete branches. Model 6 tests the hypothesis that $O M P$ was released from all selective constraints on the stem odontocete branch and evolved neutrally in all descendant odontocete lineages. Finally, Model 7 is similar to Model 5, but instead of binning the six odontocete branches with inactivating mutations into one $\omega$ category, this model allowed 
each branch with an inactivating mutation to have its own $\omega$ category (Fig. $2 \mathrm{G}$ ), as may be appropriate if $O M P$ was inactivated independently in each of these lineages (i.e., the percentage of functional and pseudogenic evolution on different branches is not assumed to be equal). Likelihood-ratio tests were used to compare nested $\omega$ branch models, and Akaike Information Criterion (AIC) scores were used to compare both nested and nonnested models. Tests for multiple likelihood-ratio tests were adjusted with a HolmBonferroni correction (Holm, 1979; Gaetano, 2013). Ancestral state reconstructions from codeml were used to estimate the numbers of nonsynonymous and synonymous substitutions on individual branches.

Based on the results of codeml analyses, we performed an additional analysis with the RELAX (Wertheim et al., 2014) subroutine of Datamonkey to confirm that selection on the $O M P$ gene was relaxed in Odontoceti versus other cetaceans and outgroups that were included in our analysis for 50 taxa (Supplementary Alignment File 4). In this analysis, we coded stem Odontoceti and crown Odontoceti branches as test branches, and all other branches in the tree were coded as reference branches).

For selection analyses of $C N G A 2$ and $C N G A 4$, two models were compared (Fig. $2 \mathrm{H}-\mathrm{I}$ ). The first included four different branch categories (background, stem Cetacea, stem and crown Mysticeti, stem and crown Odontoceti), which permitted general comparisons with the $O M P$ results. The second model included the same four branch categories, but $\omega$ was fixed at 1.0 on both stem and crown odontocete branches to test the hypothesis that these genes have evolved neutrally in Odontoceti. Statistical comparisons of models and ancestral state reconstructions were as described above for $O M P$.

\section{Results}

\subsection{Sequence alignment and inactivating mutations}

Complete coding sequences for $O M P$ were recovered for 130 taxa, and nearly complete sequences were recovered for Daubentonia madagascariensis (aye-aye), Miniopterus natalensis (Natal long-fingered bat), and Nasalis larvatus (proboscis monkey). The full alignment for these 133 OMP coding sequences is $541 \mathrm{bp}$ in length 
and is provided in Supplementary Alignment File 1. With the exception of hystricognath rodents (Cavia porcellus [domestic guinea pig], C. aperea [Brazilian guinea pig], Octodon degus [degu], Fukomys damarensis [Damaraland mole-rat], Heterocephalus glaber [naked mole-rat]), Jaculus jaculus (lesser Egyptian jerboa), Ailuropoda melanoleuca (giant panda), Kogia sima (dwarf sperm whale), and three delphinids (Orcinus orca, Tursiops truncatus, Globicephala macrorhynchus [short-finned pilot whale]), coding sequences for taxa with intact copies (i.e., without inactivating mutations) of $O M P$ are 492 base pairs (bp) (Table 2). Sequences for hystricognath rodents are slightly shorter (489 bp), as are sequences for K. sima (480 bp) and delphinids (477 bp), whereas OMP is 498 bp in J. jaculus (two 3-bp inserts) and 537 bp in $A$. melanoleuca owing to sequence divergence near the 3 ' end that results in a more downstream stop codon relative to other mammal species. Ailuropoda melanoleuca (ACTA01036580) also has a 1-bp frameshift deletion, but this appears to be due to an assembly problem; the single missing nucleotide ("G") is actually present in multiple reads (SRA) based on BLAST searches with the $M P$ scaffold sequence (ACTA01036580) for A. melanoleuca. The scaffold OMP sequences for the felids Acinonyx jubatus (cheetah) and Panthera tigris (tiger) have unusual 5' regions that are highly divergent relative to other placental mammals, including two additional felids (Lynx pardinus [Iberian lynx], Felis catus [domestic cat]), over the first $141 \mathrm{bp}$ of coding sequence. However, we constructed a revised version of $O M P$ for A. jubatus after blasting the SRA for this taxon with $F$. catus $O M P$ and then assembling the recovered reads. This updated version of the $O M P$ sequence for $A$. jubatus is more similar to other felid sequences and lacks the unusual 5' region that occurs in the original scaffold sequence (LLWD01000432). Individual sequence reads are not available for $P$. tigris on NCBI, but we presume that a similar assembly error may compromise the $O M P$ sequence for this taxon.

By contrast with other placental mammals (including mysticetes), six odontocetes have inactivating mutations in the coding sequence of OMP (Fig. 3). Physeter macrocephalus (sperm whale) has a start codon mutation (ATG $=>$ GTG) that was confirmed by sequence reads in the SRA. The nearest alternative start codon in $P$. macrocephalus is 25 codons downstream. By contrast, all non-cetaceans have putative 
ATG start codons at the same codon position that is mutated to GTG in $P$.

macrocephalus. Phocoena phocoena (harbor porpoise) also has a start codon mutation (ATG $=>$ GTG), albeit with allelic variation in the individual that was sampled (i.e., ATG and GTG). Among the river dolphins, Lipotes vexillifer (Yangtze River dolphin) has a 1bp frameshift deletion that is $68 \mathrm{bp}$ upstream from the TGA stop codon. This deletion results in 23 unique amino acids at the carboxy-terminal end of the predicted protein plus an addition of 32 amino acids that precede the delayed stop codon. Inia geoffrensis (Amazon river dolphin) has a start codon mutation (ATG $=>$ GTG), a 1-bp frameshift deletion that results in multiple premature stop codons - the earliest of which occurs at codon position 15, and a stop codon mutation (TGA => TGG). Pontoporia blainvillei (La Plata dolphin) has a 1-bp frameshift insertion that results in multiple premature stop codons, the earliest of which occurs at codon position 66. Finally, Platanista minor (Indus river dolphin) has a 2-bp frameshift deletion that results in multiple, premature stop codons, the first of which occurs at codon position 65 (Fig. 3).

We also discovered inactivating mutations in the CNGA2 and CNGA4 genes of odontocetes. For CNGA2, there are inactivating mutations in Physeter macrocephalus and both delphinids (Orcinus orca, Tursiops truncatus) (Supplementary Alignment File 2). P. macrocephalus exhibits multiple inactivating mutations including a 1-bp frameshift insertion in exon 3, a frameshift deletion that spans the 3' end of intron 4 (including splice site) plus the first 5-bp of exon 5, and frameshift deletions of 58 bp, 79 bp, 2 bp, and 34 bp in exon 6. O. orca and T. truncatus share a premature stop codon in exon 4 and a 1-bp frameshift deletion in exon 6. For $C N G A 4$, inactivating mutations occur in $T$. truncatus (1-bp frameshift deletion in exon 4), O. orca (4-bp frameshift deletion in exon 4), and Lipotes vexillifer (premature stop codon [TAC to TGA] and 1-bp frameshift deletion in exon 4, 2-bp frameshift insertion in exon 6) (Supplementary Alignment File 3). L. vexillifer and both delphinids also share a stop codon mutation (TGA to GGA) that results in predicted protein sequences that are 17 (delphinids) or 41 (Lipotes) amino acids longer than in other cetartiodactyls or perissodactyls (Supplementary Alignment File 3).

\subsection{OMP gene tree}


Figure 4 shows a RAxML phylogram (ln likelihood = -8900.796789) based on $O M P$ coding sequences that is rooted between Afrotheria and other placental mammals. The RAxML tree is consistent with the monophyly of Afrotheria, but contradicts several well-established superordinal taxa (e.g., Xenarthra, Laurasiatheria, Euarchontoglires). Some placental orders with multiple exemplars are monophyletic in the $O M P$ tree (Afrosoricida, Cetartiodactyla, Chiroptera, Eulipotyphla, Lagomorpha, Perissodactyla, Pholidota) whereas others (Carnivora, Primates, Rodentia) are not. There are also oddities within Cetacea including odontocete paraphyly and minke whale (Balaenoptera bonaerensis, B. acutorostrata) diphyly. As is often the case for gene trees based on short sequences, many of these conflicts likely result from long-branch misplacement and/or lack of phylogenetic signal and are unrelated to incomplete lineage sorting (ILS) (Gatesy and Springer, 2014; Springer and Gatesy, 2016). For example, Haplorhini (Anthropoidea + Tarsius) is diphyletic on the RAxML tree for $O M P$, but this clade is unanimously supported by 104 transposon insertions (Hartig et al., 2013) and is not a candidate for deep coalescence (Gatesy and Springer, 2014; Springer and Gatesy, 2016; Gatesy et al., 2016).

\subsection{Selection analyses}

Akaike scores suggest that codon frequency model 1 (CF1) of Yang (2007) is the most appropriate codon frequency model for $\mathrm{dN} / \mathrm{dS}$ analyses with the $O M P$ data set (Table 1). CF1 calculates equilibrium codon frequencies from average nucleotide frequencies. The relative likelihoods of three other codon frequency models - CF0, CF2, and CF3 - were all negligible (Table 1). We therefore utilized CF1 in all comparisons of competing selection models (Fig. 2) using PAML.

First, we compared a selection model with one $\omega$ category for all branches (Model 1; Fig. 2A) to a selection model with two $\omega$ categories (Model 2; Fig. 2B), a first category for background branches (non-cetaceans, stem Cetacea, and mysticetes) and a second category for stem and crown odontocete branches. The latter model corresponds to Kishida and Thewissen's (2012) echolocation-priority hypothesis wherein echolocation evolved on the stem odontocete branch and resulted in relaxed purifying selection in 
Odontoceti (Fig. 1B). Model 2 with its two $\omega$ categories is significantly better than Model $1\left(\mathrm{p}=3.58 \times 10^{-1} 10\right.$, Table 3$)$ and has a much higher relative likelihood (Table 4). We also performed a RELAX analysis on DataMonkey (Wertheim et al., 2014) and confirmed that selection was relaxed in Odontoceti $\left(\mathrm{p}=1.65 \times 10^{-11}\right)$. Next, we compared Model 2 to Model 3 (Fig. 2C), which roughly corresponds to Kishida and Thewissen's (2012) filter-feeder hypothesis. Although Model 3 has an extra parameter, it has a slightly lower likelihood (Table 3) and a lower relative likelihood than Model 2 (Table 4). In Model 3, $\omega$ for mysticete branches is only slightly higher $(0.2573)$ than the background $\omega$ value for non-cetacean mammals $(0.2252)$, with both values implying strongly negative selection on OMP. Model 4 (Fig. 2D) is more parameter rich than the strict filter-feeder hypothesis (Model 3) and allows for separate $\omega$ values on the stem Cetacea branch versus odontocete branches. Model 4 has a higher likelihood than Model 3. The likelihood for Model 4 also is slightly higher than for the echolocation-priority Model 2, but even with its two extra parameters, Model 4 is not significantly better than Model 2 (Table 3) and has a lower relative likelihood (Table 4). Importantly, Model 4 shows that the $\omega$ value for $O M P$ on the stem Cetacea branch is somewhat greater $(0.3648)$ than the background $\omega$ value (0.2255), but still implies negative selection. By contrast, the $\omega$ value for odontocetes in Model 4 is elevated to 0.8095 , a high $\omega$ value relative to the background that implies a relaxation in evolutionary constraints. The $\omega$ value for Odontoceti is less than the neutral expectation of 1.0 for a pseudogene, and this value might therefore describe a situation in which $O M P$ was ancestrally functional in stem/basal odontocetes and was then inactivated one or more times in particular odontocete lineages (i.e., odontocete branches would be a mix of functional and pseudogenic $O M P$ gene lineages; e.g., Fig. 1D).

Model 2 (Fig. 2B), which corresponds to Kishida and Thewissen's (2012) echolocation-priority hypothesis (two $\omega$ categories), was then compared to three variations of this hypothesis (Models 5-7). Model 5 (Fig. 2E) is similar to Model 2, but allows six different odontocete branches with evidence for inactivating mutations in $O M P$ to share a single, additional $\omega$ category. Model 5 is not significantly better than Model 2, and the $\omega$ value for odontocete branches without inactivating mutations (0.7631) is only slightly lower than the value (0.8772) for branches with inactivating mutations. Model 5 has a lower relative likelihood than the simpler Model 2 (Table 4). 
Model 6 (Fig. 2F) is similar to Model 2, but enforces $\omega=1.0$ for all odontocete branches to evaluate the hypothesis that $\omega$ in Odontoceti is consistent with neutrality (no negative or positive selection) albeit with a lag in clear-cut mutational evidence (e.g., frameshift mutations) for inactivation of $O M P$ (Fig. 1C). There is no significant difference between Model 2 and Model 6 (Table 3), and Model 6 has the third highest relative likelihood of all models that were evaluated. Model 7 (Fig. 2G) allows each of six branches with an inactivating mutation in $O M P$ to have a unique $\omega$. Model 7 is significantly better than Model $2(\mathrm{p}=0.0264)$ before applying a Holm-Bonferroni correction and had the highest relative likelihood (Table 4), but is not significantly better than Model 2 after applying a Holm-Bonferroni correction (Table 3). The six branches with inactivating mutations show a wide range of $\omega$ values, although sample sizes for the numbers of nonsynonymous and synonymous substitutions are generally small. For example, the $\omega$ of 999.0 for Phocoena is based on just one nonsynonymous substitution and no synonymous substitutions (Table 3).

Selection analyses with $C N G A 2$ and $C N G A 4$ were performed with four branch categories (Fig. $2 \mathrm{H}$ ) to assess whether these genes evolved under similar constraints to $O M P$ for background, stem Cetacea, Mysticeti (stem and crown), and Odontoceti (stem and crown) branches (Table 5). Purifying selection on the background (non-cetacean) branches is stronger for $C N G A 2(0.1120)$ and $C N G A 4(0.1190)$ than for $O M P(0.2255)$. The $\omega$ for stem Cetacea, in turn, is very similar for all three genes (0.3023 to 0.3648). Mysticete branches for $C N G A 2$ and $C N G A 4$ remain under purifying selection, but have higher $\omega$ values than $O M P$. Finally, odontocete branches for $C N G A 2$ and $C N G A 4$ have $\omega$ $>1$ whereas $\omega<1$ for $O M P$ (Table 5). However, in all cases these $\omega$ values for Odontoceti are not significantly different from 1.0 (Table 5).

\section{Discussion}

\subsection{OMP expression and function}

Olfactory receptor genes belong to a large multigene family, with different OR paralogues specialized for the detection of diverse odorants (Buck and Axel, 1991). 
Therefore, many OR gene copies may become pseudogenized, resulting in lost sensitivity to specific odorants rather than total anosmia (Hayden et al., 2010). By contrast, singlecopy genes in the olfactory transduction cascade are required for olfaction (Pervez et al, 2014.), and their inactivation provides compelling evidence for the complete loss of the olfactory sense. $O M P$ is a single-copy gene that is strongly expressed in vertebrate OR neurons (Reisert et al., 2007), and this implies a critical role in olfaction. Functional studies and knockouts of OMP in mouse corroborate this role (Buiakova et al., 1996; Youngentob et al., 2001, 2003). Kishida and Thewissen (2012) reported OMP sequences for five different species of odontocetes, which are thought to be anosmic, and showed that $\omega$ values are elevated in these odontocetes relative to mysticetes and non-cetaceans, both of which retain functional olfactory systems. Kishida and Thewissen (2012) also reported a high $\omega$ value on their "Eocene whale" branch with ten nonsynonymous substitutions and zero synonymous substitutions. However, Kishida and Thewissen (2012) did not find any evidence for inactivating mutations in the $O M P$ of odontocetes that they sampled. In the absence of such mutations, they suggested that OMP may have additional function(s) in anosmic odontocetes that enforce the retention of an intact $O M P$ reading frame.

Expression studies provide additional evidence that $O M P$ is pleiotropic and plays a role outside of olfaction (Baker et al., 1989; Kang et al., 2015). In particular, Kang et al. (2015) reported that $O M P$ is expressed in a wide variety of mouse tissues including heart, skeletal muscle, bladder, thymus, thyroid, testis, lung, pancreas, stomach, and duodenum. Our finding that six different odontocetes have inactivated copies of $O M P$ (see below) does not negate the expression profile for this gene that was reported by Kang et al. (2015), but does suggest that the only essential function of this gene that is maintained by natural selection is in olfaction. This conclusion assumes that the function of OMP is generally conserved across Mammalia. Because anosmia in Mammalia is restricted to just one clade (Odontoceti), relationships between genotype and phenotype cannot be corroborated by parallel evolution of the same phenotype that is tied to inactivation of the same gene in distantly related taxa. By contrast, edentulism (Deméré et al., 2008; Meredith et al., 2009, 2011b; Springer et al., 2016a) and rod monochromacy (Meredith et al., 2013; Emerling and Springer, 2014, 2015; Springer et al., 2016b) occur in diverse 
mammalian lineages and provide more independent data points for testing the essential functions of candidate tooth-specific genes and cone-specific genes, respectively.

\subsection{Inactivation of OMP, CNGA2, and CNGA4 in Cetacea}

The occurrence of inactivating mutations in the $O M P$ gene of six different lineages of Odontoceti, including four river dolphin genera, provides the first molecular evidence for pseudogenization of $O M P$ in vertebrates (Figs. 3, 5). Similarly, four odontocete species (Physeter macrocephalus, Lipotes vexillifer, Orcinus orca, Tursiops truncatus) with published genome sequences have inactivating mutations in CNGA2 and/or CNGA4, which encode subunits of CNG channels that play a critical role in the olfactory signal transduction cascade (Michalakis et al., 2006; Nache et al., 2016) (Fig. 5). Collectively, these results suggest that olfactory-specific genes in Odontoceti are in a general state of decay as expected for taxa that have lost olfactory bulbs and related olfactory structures. Our finding that $\omega$ for $O M P$ is similarly elevated on odontocete branches with and without inactivating mutations ( 0.8772 versus 0.7631 , no significant difference, Table 3) provides additional support for this hypothesis. Accordingly, we predict that more inactivating mutations will be discovered when $O M P, C N G A 2$, and CNGA4 sequences are characterized from more odontocete species.

In addition to these inactivating mutations, other molecular changes in the $O M P$ sequences of toothed whales are suggestive of a release from selective constraints on this gene. Some odontocetes with intact coding sequences for $O M P$ include in-frame deletions that are unprecedented in length among placental mammals with functional olfactory systems. Kogia sima (dwarf sperm whale) has a 12-bp deletion (Kishida and Thewissen, 2012), and a 15-bp deletion is shared by three delphinids (Globicephala macrorhynchus, Tursiops truncatus, Orcinus orca). These deletions disrupt the first $\alpha$ helix and third $\beta$-strand of OMP, respectively (Kishida and Thewissen, 2012). Also, some odontocetes with intact $O M P$ sequences have unique amino acids at positions that are otherwise $100 \%$ conserved across 116 non-odontocete, placental mammals that last shared a common ancestor $~ 90-100$ million years ago (Meredith et al., 2011a; dos Reis et al., 2012; Emerling et al., 2015; Foley et al., 2016). Berardius bairdii (Baird's beaked 
whale) possesses $\mathrm{W}$ at position 28 whereas other placentals have $\mathrm{R}, O$. orca possesses $\mathrm{C}$ at position 30 in contrast to other placental mammals with $\mathrm{R}$, and $P$. phocoena exhibits $\mathrm{K}$ at position 95 whereas all other placentals have $\mathrm{N}$.

It is unclear why inactivating mutations in $O M P$ are seemingly more common in river dolphins than in other odontocetes (Fig. 5) given that morphological structures associated with olfaction, including olfactory bulbs, are absent in all odontocetes for which relevant anatomical information has been reported (Gatesy et al., 2014). One hypothesis is that $O M P$ remains under selective constraints in odontocetes with an intact copy of $O M P$ and that OMP inactivation has preferentially affected river dolphins. However, our finding that $\mathrm{dN} / \mathrm{dS}$ is not significantly different in odontocete lineages with and without inactivating mutations in $O M P$ does not support this hypothesis (Table 3). A second hypothesis is that $O M P$ has evolved neutrally in all odontocete lineages, but there has been insufficient time for inactivating mutations to accumulate in all of these lineages (Fig. 1C). According to this hypothesis, the observed pattern for $O M P$ is simply one random outcome for a gene that is evolving neutrally in this clade.

By contrast with $O M P, C N G A 2$ and $C N G A 4$ are inactivated in both delphinids (Orcinus orca, Tursiops truncatus) with fully sequenced genomes whereas only CNGA4 is inactivated in Lipotes vexillifer, the sole river dolphin with an available genome sequence (Fig. 5). Thus, the current catalogue of inactivating mutations in olfactoryspecific genes is not skewed in favor of river dolphins for CNGA2 and CNGA4. Likewise, inactivating mutations have been documented in a variety of tooth-specific genes in mysticetes, but patterns of inactivation are different for each gene that has been examined. MMP20 is the only tooth-specific gene with a common inactivating mutation in all mysticetes, whereas other genes (AMBN, AMEL, C4orf26, ENAM) exhibit patterns of inactivation that post-date the loss of teeth and in some cases do not include all extant mysticetes (Deméré et al., 2008; Meredith et al., 2011b; Springer et al., 2016a). This is not surprising in view of Meredith et al.'s (2009) calculated rate of only 0.0081 frameshifts per kilobase per million years for neutrally evolving mysticete nuclear DNA. It is also relevant that different cone-specific genes in mysticetes exhibit different patterns of inactivating mutations, presumably because the accumulation of inactivating 
mutations lags behind the relaxation of selection on genes required for color vision (Springer et al., 2016b).

\subsection{OMP evolution and the echolocation-priority versus filter-feeder hypotheses}

Statistical tests reject the hypothesis that a single $\omega$ value describes the evolution of $O M P$ in all placental mammals, and instead favor model 2 (Fig. 2B) in which odontocetes have an elevated $\omega$ relative to other placental mammals including mysticetes (Table 3 ). This model has two $\omega$ categories and is broadly congruent with the echolocation-priority hypothesis, which predicts that $O M P$ was released from strong purifying selection with the evolution of echolocation and a reduction in the importance of olfaction on the stem odontocete branch (Fig. 1B). Our selection analyses also show lower relative likelihoods for the filter-feeder hypothesis (Models 3, 4; Figs. 1A, 2C-D) than for different variations of the echolocation-priority hypothesis (Models 2, 5-7; Fig. 2B, E-G) (Table 4), and suggest that the $\omega$ value on the stem Cetacea branch is only slightly elevated (0.3648) relative to the background $\omega$ in outgroups (0.2255). Model 7 , which is a variation of the echolocation-priority hypothesis that allows for independent inactivation of $O M P$ in several odontocete lineages (Figs. 1D, 2G), has a relative likelihood that is $\sim 12 \mathrm{X}$ higher than the filter-feeder hypothesis (Table 4).

By contrast, Kishida and Thewissen (2012) favored the filter-feeder hypothesis and reported a much higher $\omega$ (10 nonsynonymous substitutions, 0 synonymous substitutions) on their "Eocene whale" branch, which includes the stem branches to both Cetacea and Cetancodonta (Cetacea + Hippopotamidae) owing to the absence of a hippopotamid in their analysis. However, this analysis (their figure 3) only included four outgroups (mouse, human, dog, cow), one mysticete (minke whale), and two odontocetes (Dall's porpoise, Baird's beaked whale). The more complete taxon sampling that was included in our data set resulted in different estimates for the numbers of nonsynonymous and synonymous substitutions on the "Eocene whale" branch (= stem Cetancodonta + stem Cetacea in our analysis). Ancestral state reconstructions based on codeml suggest that there were 3 nonsynonymous and 0 synonymous substitutions on the stem cetancodontan branch, and 6 nonsynonymous and 4 synonymous substitutions on the 
stem cetacean branch. Based on our selection analyses with an expanded data set, there is now more support for the echolocation-priority hypothesis than for the filter-feeder hypothesis (Table 4).

Among the four Models $(2,5-7)$ that represent variants of the echolocationpriority hypothesis for $O M P$, Model 7 has the highest relative likelihood (Table 4) and is consistent with independent inactivation of this gene in different odontocete lineages. Specifically, Model 7 suggests that $O M P$ was under strong purifying selection in Platanista, as may be expected if Hoch's (2000) "platanistoid" fossil with putatively functional olfaction is a close relative of Platanista. Indeed, the $\omega$ value on the Platanista branch is lower (0.1752) than the background rate of purifying selection (0.2310) in taxa with functional olfaction, which suggests that $O M P$ was only recently inactivated in the Platanista lineage. However, Model 7 is not significantly better than Model 2 based on a likelihood-ratio test (Table 3).

Our results favor the echolocation-priority hypothesis for the evolution of $O M P$ in odontocetes, and further suggest that two other olfactory-specific genes, CNGA2 and $C N G A 4$, are inactivated in some odontocetes. By contrast, other molecular components of the olfactory system were pseudogenized earlier in the evolutionary history of Cetacea (i.e., stem Cetacea branch) including an initial reduction in the repertoire of functional OR genes (Kishida et al., 2007; McGowen et al., 2008; Hayden et al., 2010). More recently, Kishida et al. (2015) reported that the olfactory-related genes OMACS, NQO1, and various TAAR loci, were pseudogenized very early during the transition from a terrestrial to fully aquatic lifestyle. These molecular results, in combination with fossil evidence, suggest that the degradation of olfaction in Cetacea has a long and complicated history (Kishida et al., 2015). It will be important in future studies to determine whether any single-copy genes in the olfactory signal transduction cascade show evidence for shared inactivation in all extant odontocetes to test whether loss of olfaction occurred in lockstep with the evolution of echolocation on the stem odontocete branch (Model 2; Fig. 2B), or whether the sense of smell was independently lost multiple times in different crown odontocete lineages as is suggested by Model 7 (Figs. 1D, 2G).

\subsection{Conclusions}


With the move from a terrestrial to an obligatory aquatic lifestyle, striking changes in 'sensory genes' that are integral to sight (Meredith et al., 2013; Emerling and Springer, 2015; Springer et al., 2016b), olfaction (Kishida et al., 2007, 2015; McGowen et al., 2008; Hayden et al., 2010), vomeronasal detection of pheromones (Yu et al., 2010; Kishida et al., 2015), taste (Jiang et al., 2012; Feng et al., 2014; Kishida et al., 2015), and audition (Li et al., 2010; Liu et al., 2010; Davies et al., 2012) have been recorded in the genomes of cetaceans. These examples include positive selection for functional changes, degradation of genes that are presumably no longer necessary in the aquatic realm, and possible tuning of function by subtraction of loci through pseudogenization (McGowen et al., 2014). By surveying $O M P$ from a broader array of cetacean diversity and outgroups, complemented by sampling $C N G A 2$ and $C N G A 4$ from taxa with available genome sequences, our understanding of the evolutionary history of these genes and the evolutionary history of Cetacea are more refined (Fig. 5; Tables 3-4). In particular, the molecular results corroborate the hypothesis that various extant toothed whales are indeed anosmic, that this condition may have evolved convergently within Odontoceti, and that the primary functions of $O M P, C N G A 2$, and $C N G A 4$ are olfaction-related. We predict that as more genomic data from Cetacea are compiled, a still richer reconstruction of the molecular evolutionary events that underlie the unique sensory specializations of this clade will emerge, especially if these molecular data are integrated with the impressive fossil record of Cetacea (e.g., Deméré et al., 2008; Meredith et al., 2009, 2011b; Kishida and Thewissen, 2012; Gatesy et al., 2013; McGowen et al., 2014; Kishida et al., 2015).

\section{Acknowledgments}

This work was supported by NSF grant DEB-1457735 to J.G. and M.S.S. Paintings are by C. Buell. We thank J. Wertheim for assistance with RELAX. J. Geisler and two anonymous reviewers provided helpful comments on an earlier draft of this manuscript. For DNA samples, we thank G. Amato, A. Berta, G. Braulik, L. Chou, P. Morin, K. Robertson, U. Árnason, Southwest Fisheries Science Center - LaJolla, the 
New York Zoological Society, The Marine Mammal Center - Sausalito, Smithsonian

Institution Division of Mammals, World Wildlife Fund, South Australian Museum, and Northeast Fisheries Science Center - Stranding Network.

\section{References}

Abdus-Saboor, I., Al Nufal, M.J., Agha, M.V., de Brimont, M.R., Fleischmann, A., Shykind, B.M., 2016. An expression refinement process ensures singular odorant receptor gene choice. Curr. Biol. 26, 1083-1090.

Bajpai, S., Thewissen, J.G.M., Conley, R.W., 2011. Cranial anatomy of middle Eocene Remingtonocetus (Cetacea, Mammalia) from Kutch, India. J. Paleontol. 85, 703-718.

Baker, H., Grillo, M., Margolis, F.L., 1989. Biochemical and immunocytochemical characterization of olfactory marker protein in the rodent central nervous system. J. Comp. Neurol. 285, 246-261.

Berta, A., Ekdale, E.G., Cranford, T.W., 2014. Review of the cetacean nose: form, function, and evolution. Anat. Rec. 297, 2205-2215.

Bianucci, G., Gingerich, P.D., 2011. Aegyptocetus tarfa, n. gen. et sp. (Mammalia, Cetacea), from the middle Eocene of Egypt: clinorhynchy, olfaction, and hearing in a protocetid whale. J. Vertebr. Paleontol. 31, 1173-1188.

Buck, L., Axel, R., 1991. A novel multigene family may encode odorant receptors: a molecular basis for odor recognition. Cell 65, 175-187.

Buiakova, O.I., Baker, H., Scott, J.W., Farbman, A., Kream, R., Grillo, M., Franzen, L., Richman, M., Davis, L.M., Abbondanzo, S., Stewart, C.L., Margolis, F.L., 1996. Olfactory marker protein (OMP) gene deletion causes altered physiological activity of olfactory sensory neurons. Proc. Natl. Acad. Sci. USA 93, 9858-9863. 
Cave, A.J.E., 1988. Note on olfactory activity in mysticetes. J. Zool. Lond. 214, 307-311.

Danciger, E., Mettling, C., Vidal, M., Morris, R., Margolis, F., 1989. Olfactory marker protein gene: Its structure and olfactory neuron-specific expression in transgenic mice. Proc. Natl. Acad. Sci. U.S.A. 86, 8565-8569.

Davies, K.T.J., Cotton, J.A., Kirwan, J.D., Teeling, E.C., Rossiter, S.J., 2012. Parallel signatures of sequence evolution among hearing genes in echolocating mammals: an emerging model of genetic convergence. Heredity 108, 480-489.

Deméré, T.A., McGowen, M.R., Berta, A., Gatesy, J., 2008. Morphological and molecular evidence for a stepwise evolutionary transition from teeth to baleen in mysticete whales. Syst. Biol. 57, 15-37.

dos Reis, M., Inoue, J., Hasegawa, M., Asher, R.J., Donoghue, P.C.J., Yang, Z., 2012. Phylogenomic datasets provide both precision and accuracy in estimating the timescale of placental mammal phylogeny. Proc. R. Soc. B 279, 3491-3500.

Emerling, C.A., Springer, M.S., 2014. Eyes underground: regression of visual protein networks in subterranean mammals. Mol. Phylogenet. Evol. 78, 260-270.

Emerling, C.A., Springer, M.S., 2015. Genomic evidence for rod monochromacy in sloths and armadillos suggests early subterranean history for Xenarthra. Proc. R. Soc. B $282,20142192$.

Feng, P., Zheng, J., Rossiter, S.J., Wang, D., Zhao, H., 2014. Massive losses of taste receptor genes in toothed and baleen whales. Genome Biol Evol. 6, 1254-65.

Flower, W.H., 1883. On whales, past and present, and their probable origin. Proc. R. Inst. Great Brit. 10, 360-376. 
Foote, A.D., Liu, Y., Thomas, G.W.C., Vinar, T., Alföldi, J., Deng, J., Dugan, S., van Elk, C.E., Hunter, M.E., Joshi, V., et al., 2015. Convergent evolution of the genomes of marine mammals. Nat. Genet. 47, 272-275.

Fordyce, R.E., 1994. Waipatia maerewhenua, new genus and new species (Waipatiidae, new family), an archaic late Oligocene dolphin (Cetacea: Odontoceti: Platanistoidea) from New Zealand. In: Berta, A., Deméré, T.A. (Eds.), Contributions in Marine Mammal Paleontology Honoring Frank Whitmore Jr. Proc. San Diego Soc. Nat. Hist., vol. 29, pp. $147-176$.

Gaetano, J., 2013. Holm-Bonferroni Sequential Correction: An EXCEL Calculator (1.1) [Microsoft Excel Workbook]. doi: http://dx.doi.org/10.13140/RG.2.1.4466.9927.

Gatesy, J., Springer, M.S., 2014. Phylogenetic analysis at deep timescales: unreliable gene trees, bypassed hidden support, and the coalescence/concatalescence conundrum. Mol. Phylogenet. Evol. 80, 231-266.

Gatesy, J., Geisler, J.H., Chang, J., Buell, C., Berta, A., Meredith, R.W., Springer, M.S., McGowen, M.R., 2013. A phylogenetic blueprint for a modern whale. Mol. Phylogenet. Evol. 66, 479-506.

Gatesy, J., Meredith, R.W., Janecka, J.E., Simmons, M.P., Murphy, W.J., Springer, M.S., 2016. Resolution of a concatenation/coalescence kerfuffle: partitioned coalescence support and a robust family-level tree for Mammalia. Cladistics DOI: 10.1111/cla.12170.

Geisler, J.H., Sanders, A.E., 2003. Morphological evidence for the phylogeny of Cetacea. J. Mammal. Evol. 10, 23-129. 
Geisler, J.H., McGowen, M.R., Yang, G., Gatesy, J., 2011. A supermatrix analysis of genomic, morphological, and paleontological data from crown Cetacea. BMC Evol. Biol. 11,112 .

Godfrey, S.J., 2013. On the olfactory apparatus in the Miocene odontocete Squalodon sp. (Squalodontidae). C. R. Palevol 12, 519-530.

Godfrey, S.J., Geisler, J., Fitzgerald, E.M., 2013. On the olfactory anatomy in an archaic whale (Protocetidae, Cetacea) and the minke whale Balaenoptera acutorostrata (Balaenopteridae, Cetacea). Anat. Rec. 296, 257-272.

Hartig, G., Churakov, G., Warren, W.C., Brosius, J., Makalowski, W., Schmitz, J., 2013. Retrophylogenomics place tarsiers on the evolutionary branch of anthropoids. Sci. Rep. $3,1756$.

Hassanin, A., Delsuc, F., Ropiquet, A.,Hammer, C., van Vuuren, B.J., Matthee, C., RuizGarcia, M., Catzeflis, F., Areskoug, V., Nguyen, T.T., Couloux, A., 2012. Pattern and timing of diversification of Cetartiodactyla (Mammalia, Laurasiatheria), as revealed by a comprehensive analysis of mitochondrial genomes. C. R. Biol. 335, 32-50.

Hayden, S., Bekaert, M., Crider, T.A., Mariani, S., Murphy, W.J., Teeling, E.C., 2010. Ecological adaptation determines functional mammalian olfactory subgenomes. Genome Res. 20,1-9.

Heyning, J.E., 1997. Sperm whale phylogeny revisited: analysis of the morphological evidence. Mar. Mammal Sci. 13, 596-613.

Hoch, E., 2000. Olfaction in whales: evidence from a young odontocete of the late Oligocene North Sea. Hist. Biol. 14, 67-89. 
Holm, S., 1979. A simple sequentially rejective multiple test procedure. Scandinavian J. Stat. 6, 65-70.

Jiang, P., Josue, J., Li, X., Glaser, D., Li, W., Brand, J.G., Margoiskee, R.F., Reed, D.R., Beauchamp, G.K., 2012. Major taste loss in carnivorous mammals. Proc. Natl. Acad. Sci. USA 109, 4956-4961.

Johnson, W.E., Eizirik, E., Pecon-Slattery, J., Murphy, W.J., Antunes, A., Teeling, E., O'Brien, S.J., 2006. The late Miocene radiation of modern Felidae: a genetic assessment. Science $311,73-77$.

Kang, N., Kim, H., Jae, Y., Lee, N., Ku, C.R., Margolis, F., Lee, E.J., Bahk, Y.Y., Kim, M.-S., Koo, J., 2015. Olfactory marker protein expression is an indicator of olfactory receptor-associated events in non-olfactory tissues. PLoS ONE 10, e0116097.

Katoh, K., Misawa, K., Kuma, K., Miyata, T., 2002. MAFFT: a novel method for rapid multiple sequence alignment based on fast Fourier transform. Nucleic Acids Res. 30, 3059-3066.

Keane, M., Semeiks, J., Webb, A.E., Li, Y.I., Quesada, V., Craig, T., Madsen, L.B., van Dam, S., Brawand, D., Marques, P.I., Michalak, P., Kang, L., Bhak, J., Yim, Y.-S., Grishin, N.V., Hielsen, N.H., Heide-Jørgensen, Oziolor, E.M., Matson, C.W., Church, G.M., Stuart, G.W., Patton, J.C., George, J.C., Suydam, R., Larsen, K., López-Otín, C., O’Connell, J.O., Bickham, J.W., Thomsen, B., de Magalhães, J.P., 2015. Insights into the evolution of longevity from the bowhead whale genome. Cell Rep. 10, 112-122.

Kearse, M., Moir, R., Wilson, A., Stones-Havas, S., Cheung, M., Sturrock, S., Buxton, S., Cooper, A., Markowitz, S., Duran, C., Thierer, T., Ashton, B., Mentjies, P., Drummond, A., 2012. Geneious basic: an integrated and extendable desktop software platform for the organization and analysis of sequence data. Bioinformatics 28, 1647-1649. 
Kishida, T., Thewissen, J.G.M., 2012. Evolutionary changes of the importance of olfaction in cetaceans based on the olfactory marker protein gene. Gene 492, 349-353.

Kishida, T., Kubota, S., Shirayama, Y., Fukami, H., 2007. The olfactory receptor gene repertoires in secondary-adapted marine vertebrates: evidence for reduction of the functional proportions in cetaceans. Biol. Lett. 3, 428-430.

Kishida, T., Thewissen, J.G.M., Hayakawa, T., Imai, H., Agata, K., 2015. Aquatic adaptation and the evolution of smell and taste in whales. Zool. Lett. 1, 9.

Li, Y., Liu, Z., Shi, P., Zhang, J., 2010. The hearing gene Prestin unites echolocating bats and whales. Curr. Biol. 20, R55-R56.

Liu, Y., Rossiter, S., Han, X., Cotton, J., Zhang, S., 2010. Cetaceans on a molecular fast track to ultrasonic hearing. Curr. Biol. 20, 1834-1839.

Michalakis, S., Reisert, J., Geiger, H., Wetzel, C., Zong, X., Bradley, J., Spehr, M., Hüttl, S., Gerstner, A., Pfeifer, A., Hatt, H., Yau, K.-W., Biel, M., 2006. Loss of CNGB1 protein leads to olfactory dysfunction and subciliary cyclic nucleotide-gated channel trapping. J. Biol. Chem. 281, 35156-35166.

McGowen, M.R., Clark, C., Gatesy, J., 2008. The vestigial olfactory receptor subgenome of odontocete whales: phylogenetic congruence between genetree reconciliation and supermatrix methods. Syst. Biol. 57, 574-590.

McGowen, M.R., Spaulding, M., Gatesy, J., 2009. Divergence time estimation and a comprehensive molecular tree of extant cetaceans. Mol. Phylogenet. Evol. 53, 891-906.

McGowen, M.R., Gatesy, J., Wildman, D.E., 2014. Molecular evolution tracks macroevolutionary transitions in Cetacea. Trends Ecol. Evol. 29, 336-346. 
Meredith, R.W., Gatesy, J., Murphy, W.J., Ryder, O.A., Springer, M.S., 2009. Molecular decay of the tooth gene enamelin (ENAM) mirrors the loss of enamel in the fossil record of placental mammals. PLoS Genet. 5 (9), e1000634.

Meredith, R.W., Janecka, J.E., Gatesy, J., Ryder, O.A., Fisher, C.A., Teeling, E.C., Goodbla, A., Eizirik, E., Simão, T.L.L., Stadler, T., Rabosky, D.L., Honeycutt, R.L., Flynn, J.J., Ingram, C.M., Steiner, C., Williams, T.L., Robinson, T.J., Burk-Herrick, A., Westerman, M., Ayoub, N.A., Springer, M.S., Murphy, W.J., 2011a. Impacts of the Cretaceous terrestrial revolution and KPg extinction on mammal diversification. Science $334,521-524$.

Meredith, R.W., Gatesy, J., Cheng, J., Springer, M.S., 2011b. Pseudogenization of the tooth gene enamelysin $(M M P 20)$ in the common ancestor of extant baleen whales. Proc. R. Soc. B 278, 993-1002.

Miller, M.A., Pfeiffer, W., Schwartz, T., 2010. "Creating the CIPRES Science Gateway for inference of large phylogenetic trees" in Proceedings of the Gateway Computing Environments Workshop (GCE), 14 Nov. 2010, New Orleans, LA pp 1-8.

Nache, V., Wongsamitku, Kusch, J., Zimmer, T., Schwede, F., Benndorf, K., 2016.

Deciphering the function of the CNGB1b subunit in olfactory CNG channels. Sci. Rep. 6, 29378.

Oelschläger, H.A., 1992. Development of the olfactory and terminalis systems in whales and dolphins. In: Doty, R.L., Müller-Schwarze, D. (Eds.), Chemical Signals in Verterbrates VI. Plenum Press, New York, pp. 141-147.

Oelschläger, H.A., 2008. The dolphin brain - a challenge for synthetic neurobiology. Brain Res. Bull. 75, 450-459. 
Oelschläger, H.A., Buhl, E.H., Dann, J.F., 1987. Development of the nervus terminalis in mammals including toothed whales and humans. Ann. N.Y. Acad. Sci. 519, 447-464.

Pervez, N., Ham, H-G., Kim, S., 2014. Interplay of signaling molecules in olfactory sensory neuron toward signal amplification. Hanyang Med. Rev. 37, 137-142.

Reisert, J., Yau, K.-W., Margolis, F.L., 2007. Olfactory marker protein modulates the cAMP kinetics of the odour-induced response in cilia of mouse olfactory receptor neurons. J. Physiol. 583, 731-740.

Slijper, E.J., 1962. Whales, second ed. Cornell University Press, Ithaca, NY.

Springer, M.S., Gatesy, J., 2016. The gene tree delusion. Mol. Phylogenet. Evol. 94, 133.

Springer, M.S., Emerling, C.A., Fugate, N., Patel, R., Starrett, J., Morin, P.A., Hayashi, C., Gatesy, J., 2016b. Inactivation of cone-specific phototransduction genes in rod monochromatic cetaceans. Front. Ecol. Evol. 4, 61.

Springer, M.S., Starrett, J., Morin, P.A., Lanzetti, A., Hayashi, C., Gatesy, J., $2016 a$. Inactivation of C4orf26 in toothless placental mammals. Mol. Phylogenet. Evol. 95, 3445.

Stamatakis, A., 2006. RAxML-VI-HPC: maximum likelihood-based phylogenetic analyses with thousands of taxa and mixed models. Bioinformatics 22, 2688-2690.

Stamatakis, A., Hoover, P., Rougemont, J., 2008. A rapid bootstrap algorithm for the RAxML web servers. Syst. Biol. 57, 758-771. 
Steeman, M.E., Hebsgaard, M.B., Fordyce, R.E., Ho, S.Y.W., Rabosky, D.L., Nielsen, R., Rahbek, C., Glenner, H., Sørensen, M.V., Willerslev, E., 2009. Radiation of extant cetaceans driven by restructuring of the oceans. Syst. Biol. 58, 573- 585 .

Swofford, D.L., 2002. PAUP*. Phylogenetic Analysis Using Parsimony (* and Other Methods). Sinauer Associates, Sunderland, MA.

Tan, L., Li, Q., Xie, S., 2015. Olfactory sensory neurons transiently express multiple olfactory receptors during development. Mol. Syst. Biol. 11, 844.

Thewissen, J.G.M., George, J., Rosa, C., Kishida, T., 2010. Olfaction and brain size in the bowhead whale (Balaena mysticetus). Mar. Mamm. Sci. 27, 282-294.

Uhen, M.D., 2010. The origin(s) of whales. Annu. Rev. Earth Planet. Sci. 38, 189-219.

Wertheim, J.O., Murrell, B., Smith, M.D., Pond, S.L.K., Scheffler, K., 2014. RELAX:

Detecting relaxed selection in a phylogenetic framework. Mol. Biol. Evol. 32, 820-832.

Yang, Z., 2007. PAML 4: phylogenetic analysis by maximum likelihood. Mol. Biol. Evol. 24, 1586-1591.

Yim, H.-S., Cho, Y.S., Guang, X., Kang, S.G., Jeong, J.-Y., Cha, S.-S., Oh, H.-M., Lee, J.-H., Yang, E.C., Kwon, K.K., et al., 2014. Minke whale genome and aquatic adaptation in cetaceans. Nat. Genet. 46, 88-92.

Youngentob, S.L., Margolis, F.L., Youngentob, L.M., 2001. OMP gene deletion results in an alteration in odorant quality perception. Behav Neurosci 115, 626-631.

Youngentob, S.L., Kent, P.F., Margolis, F.L., 2003. OMP gene deletion results in an alteration in odorant-induced mucosal activity patterns. J. Neurophysiol. 90, 3864-3873. 
Yu, L., Jin, W., Wang, J., Zhang, X., Chen, M., Zhou, Z., Lee, H., Lee, M., Zhang, Y., 2010. Characterization of TRPC2, an essential genetic component of VNS chemoreception, provides insights into the evolution of pheromonal olfaction in secondary-adapted marine mammals. Mol. Biol. Evol. 27, 1467-1477.

Zhou, X., Sun, F., Xu, S., Fan, G., Zhu, K., Liu, X., Chen, Y., Shi, C., Yang, Y., Huang, Z., et al., 2013. Baiji genomes reveal low genetic variability and new insights into secondary aquatic adaptations. Nat. Comm. 4, 2708.

\section{Figure Legends}

Fig. 1. Different hypotheses for the evolution of $O M P$ in Cetacea. The filter-feeder hypothesis (A) posits a transition from ancestral negative selection (dark green) in outgroups, to relaxed selective constraints (light green) on the "Eocene whale" branch linked to a move to the aquatic realm, and a more recent transition back to strong negative selection in mysticetes (baleen whales) that are thought to use olfaction to detect airborne odorants from prey. The echolocation-priority hypothesis (B) posits a major transition from strong selective constraints on $O M P$ in taxa that retain the sense of smell (dark green), to a relaxation of selective constraints (light green) on the stem odontocete branch with the evolution of echolocation and less reliance on olfaction. (C) and (D) represent variations of the echolocation-priority hypothesis and show alternative reconstructions of $O M P$ evolution given a denser sampling of taxa. Black triangles represent inactivating mutations, and red branches indicate neutral evolution. A single release from selective constraints on the stem odontocete branch with lags in mutational evidence for inactivation of $O M P$ is portrayed in $(\mathrm{C})$, and parallel inactivation of $O M P$ by multiple independent mutations within crown Odontoceti is shown in (D). The latter might be expected if functional olfactory anatomy was lost in parallel within Odontoceti. (C) and (D) demonstrate that addition of a hippopotamid to the sample of taxa divides the "Eocene whale" branch in scenarios (A) and (B) into two lineages, stem Cetancodonta and stem Cetacea. 
Fig. 2. Graphical depiction of nine selection models that were evaluated with PAML (Yang, 2007). Seven models were assessed for $O M P$ (A-G), and two were compared for CNGA2 and CNGA4 (H-I). For each model, the coloring of branches indicates different $\mathrm{dN} / \mathrm{dS}(\omega)$ categories; $\omega$ was estimated for each category, except for red branches in models $\mathrm{F}$ and I where $\omega$ was fixed at 1.0 (neutral evolution). Black triangles on branches mark inferred inactivating mutations for $O M P$ and $C N G A 2+C N G A 4$ (deltran parsimony optimization). Fully aquatic environment, echolocation, and baleen also are optimized on each tree to provide context for the various branch categories.

Fig. 3. Inactivating mutations in $O M P$ sequences of odontocete cetaceans. Altered start codons (pink), stop codon (purple), frameshift deletions (green), and a frameshift insertion (blue) are shown. Sequences are numbered from the first base of the ancestral start codon and correspond to Supplementary Alignment File 1.

Fig. 4. ML phylogram based on $O M P$ coding sequences of placental mammals. Colored rectangles delimit members of higher-level taxa; asterisks denote taxa that are not monophyletic. Colored branches connect members of Laurasiatheria (Cetacea [blue], non-cetacean laurasiatheres [green]) and Euarchontoglires (brown).

Fig. 5. Parsimony optimization of inactivating mutations in $O M P$ (pink), CNGA2 (red), and $C N G A 4$ (yellow) onto a species tree for Cetacea (Gatesy et al., 2013). Altered start codons ('START'), stop codons (STOP), and splice sites (SPL), mutations to premature stop codons (PST), and frameshift insertions (INS) and deletions (DEL) are mapped by deltran to particular branches of the tree. Alignments for inactivating mutations in $O M P$ are shown in Figure 3. Divergence times in the tree are from McGowen et al. (2009) and Steeman et al. (2010).

Glossary

Echolocation-priority hypothesis: the hypothesis that the acquisition of echolocation in odontocetes resulted in a reduction in the importance of olfaction. 
Filter-feeder hypothesis: the hypothesis that olfaction is important for filter-feeding mysticetes to locate their prey, but has been less important for odontocetes and stem cetaceans. 
Figure 2

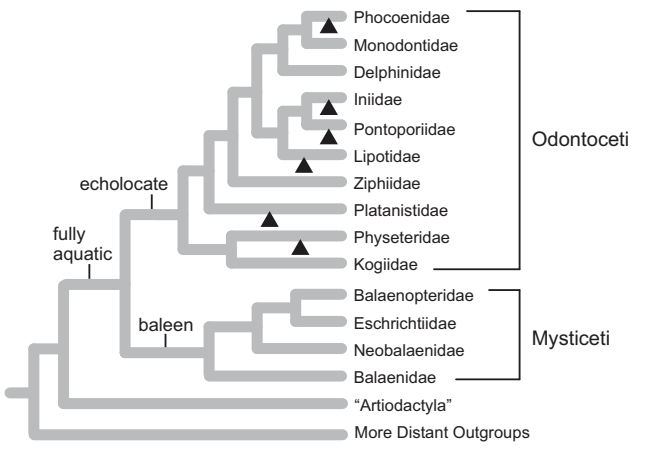

A) OMP Model 1: one dN/dS value

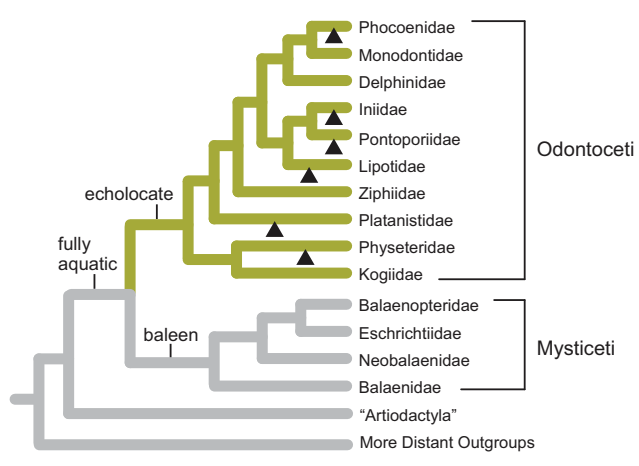

B) OMP Model 2: two dN/dS values

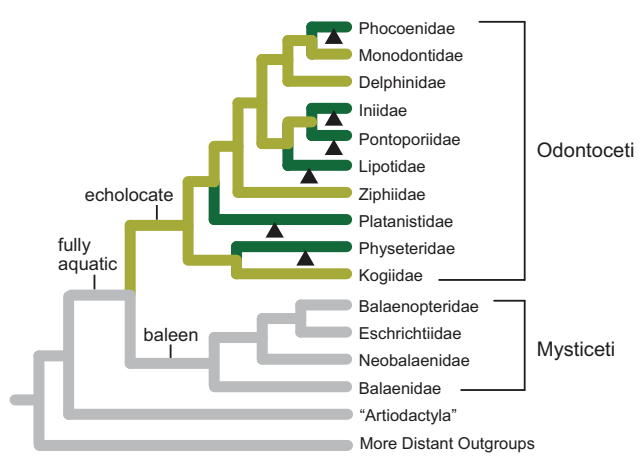

E) OMP Model 5: three $\mathrm{dN} / \mathrm{dS}$ values

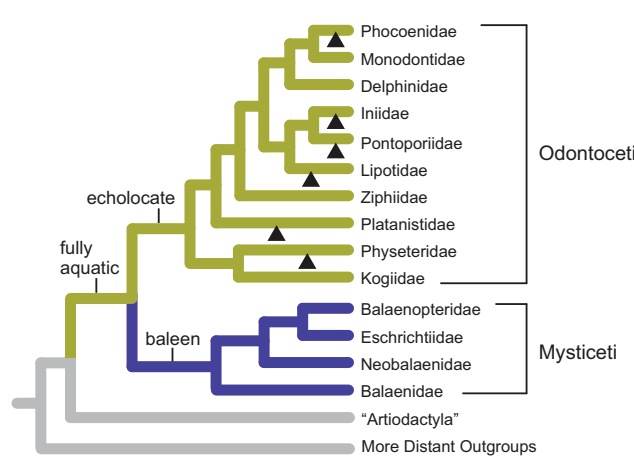

C) OMP Model 3: three $\mathrm{dN} / \mathrm{dS}$ values

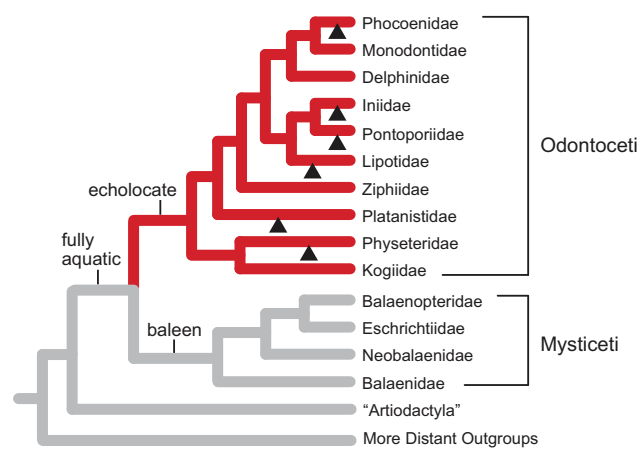

F) OMP Model 6: two dN/dS values; red fixed at 1.0

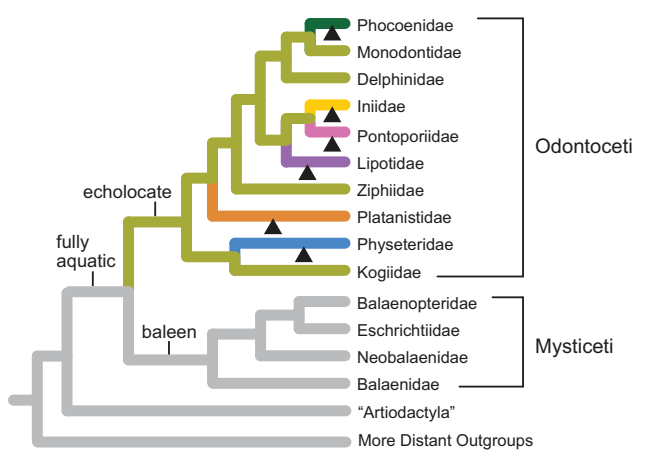

G) OMP Model 7: eight dN/dS values

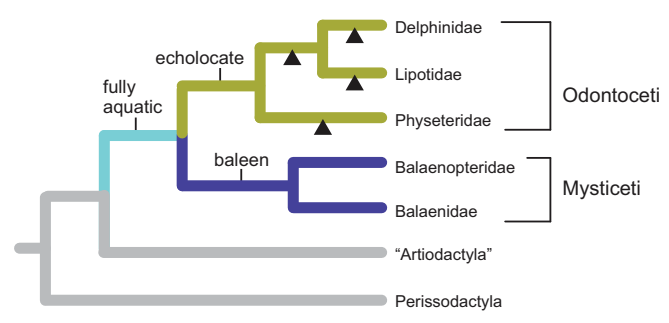

H) $C N G A 2+C N G A 4$ Model 1: four dN/dS values

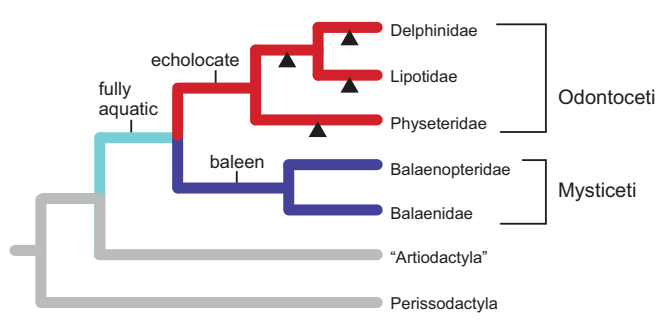

I) $C N G A 2+C N G A 4$ Model 2: four dN/dS values; red fixed at 1.0 
Choeropsis liberiensis Balaenoptera musculus Caperea marginata Balaena mysticetus Kogia sima Physeter macrocephalus Platanista minor Mesoplodon bidens Tasmacetus shepherdi ziphius cavirostris Berardius bairdii Inia geoffrensis Lipotes vexillifer Pontoporia blainvillei Delphinapterus leucas Phocoenoides dalli Neophocaena phocaenoides Phocoena phocoena Orcinus orca Globicephala macrorhynchus Tursiops truncatus
1

I

ATGGCGGAGGAC ATGGCGGAGGAC ATGGCGGAGGAC ATGGCGGAGGAC ATGGCGGAGGAT GTGGCGGAGGAC ATGGCGGAGGAC ATGGCGGAGGAC ATGGCGGAGGAC ATGGCAGAGAAT ATGGCGGAGGAC GTGGC-GAGGAC ATGGCGGAGGAC ATGGCGGAGGAC ATGGCGGAGGAC ATGGCGGAGGAC ATGGCGGAGGAC RTGGCGGAGGAC ATGGCGGAGGAC ATGGCGGAGAAC ATGGCGGAGGAC
41

CGACATG-CCGC CGACATG-CCCC CGACATG-CCCC CGACATG-CCCC CGACATG-CCCC CGACACG-CCCC CGACATG-CCCC CGACATG-CCCC CGACATG-CCCC CGACATG-CCCC CGACATG-CCCC CGACATG-CCCC TGACGTG-CCCC CGACATGCCCCC GGACATG-CCCC GGACATG-CCCC GGACATG-CCCC GGACATG-CCCC GGACACG-CCCC GGACACG-CCCC GGACACG-CCCC
91 GCGTGGAGAGC GCGTGGAGAGT GCGTGGAGAGT GCGTGGAGAGT GCCTGGAGAGC GCCTGGAGAGT GCGTG--GAGT GCGTGGAGAGT GCGTGGAGAGT GCGTGGAGAGT GCGTGGAGAGT GCGTGGAGAGT GCGTGGAGAGT GCGTGGAGAGT GCGTGGAGAGT GCGCGGAGAGT GCGCGGAGAGT GCGCGGAGAGT GCGTGGAGAGT GCGTGGAGAGT GCGTGGAGAGT
427

$437 \quad 504$

GTACTTCCTCC GTACTTCCTCA GTACTTCCTTA GTACTTCCTCA GTACTTCCTCA GTACTTCCTCA GTACTTCCTCA GTACTTCCTCA GTACTTCCTCA GTACTTCCTCA GTACTTCCTCA GTACTTCCTCA GTAC-TCCTCA GTACTTCCTCA GTACTTCCTCA GTACTTCCTCA GTACTTCCTCA GTACTTCCTCA GTACTTCCTCA GTACTTCCTCA GTACTTCCTCA
TGA TGA TGA TGA TGA TGA TGA TGA TGA TGA TGA TGG TGA TGA TGA TGA TGA TGA TGA TGA TGA 
$V=O M P$ mutation

$\nabla=C N G A 2$ mutation

$V=$ CNGA4 mutation
.
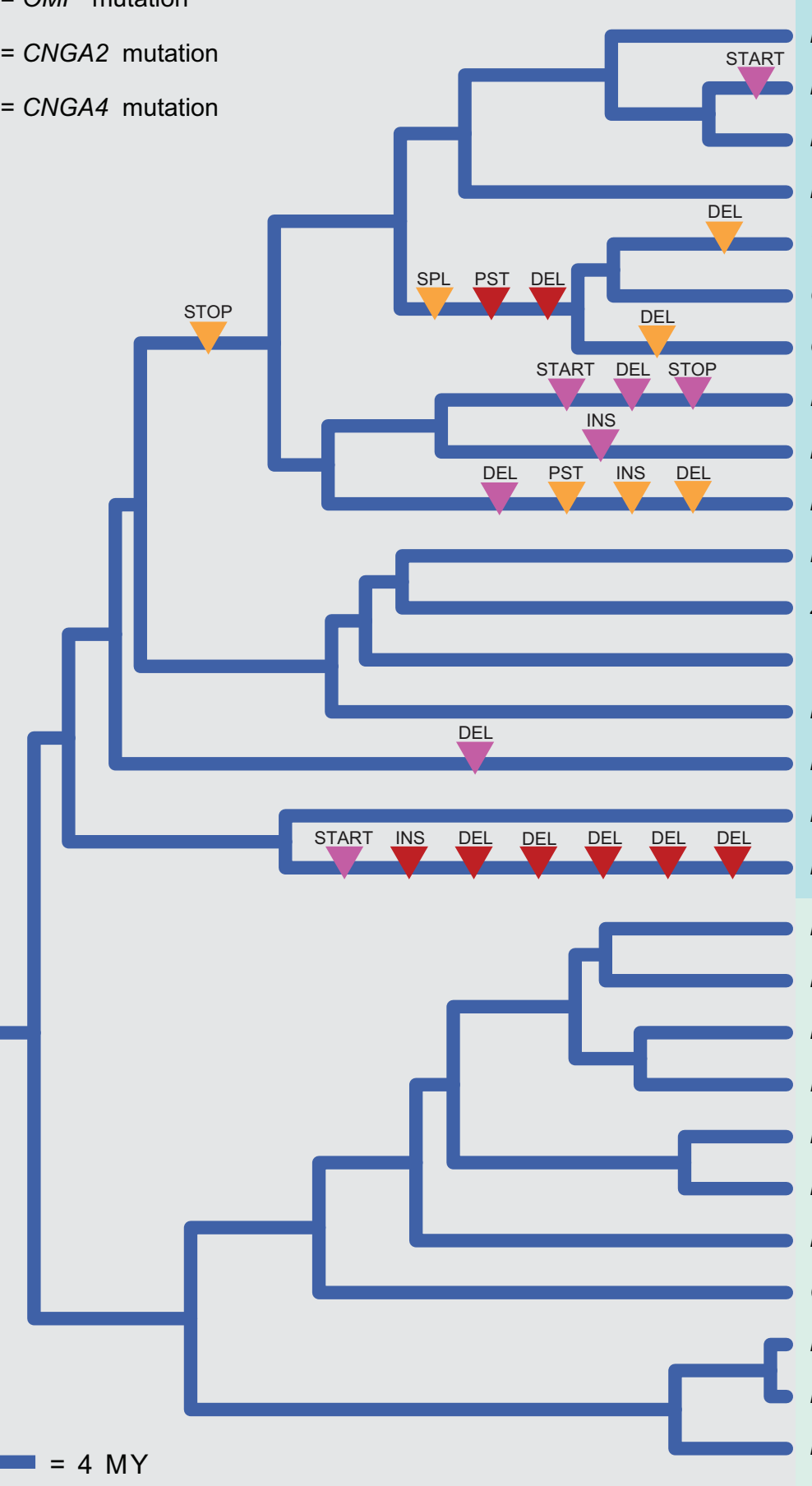

Neophocaena phocaenoides Phocoena phocoena

Phocoenoides dalli

Delphinapterus leucas

Tursiops truncatus *

Globicephala macrorhynchus

Orcinus orca *

Inia geoffrensis

Pontoporia blainvillei

Lipotes vexillifer*

-

Mesoplodon bidens

Ziphius cavirostris

Tasmacetus shepherdi

Berardius bairdii

Platanista minor

Kogia sima

Physeter macrocephalus *

Balaenoptera brydei

Balaenoptera musculus

Balaenoptera physalus

Megaptera novaeangliae

Balaenoptera acutorostrata *

Balaenoptera bonaerensis *

Eschrichtius robustus

Caperea marginata

Eubalaena glacialis

Eubalaena australis

Balaena mysticetus *

\section{Odontoceti}

Phocoenidae

Monodontidae

Delphinidae

- Iniidae

Pontoporiidae

Lipotidae

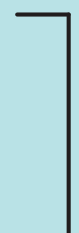

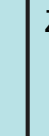

Ziphiidae

Platanistidae

Kogiidae

Physeteridae
Balaenopteridae
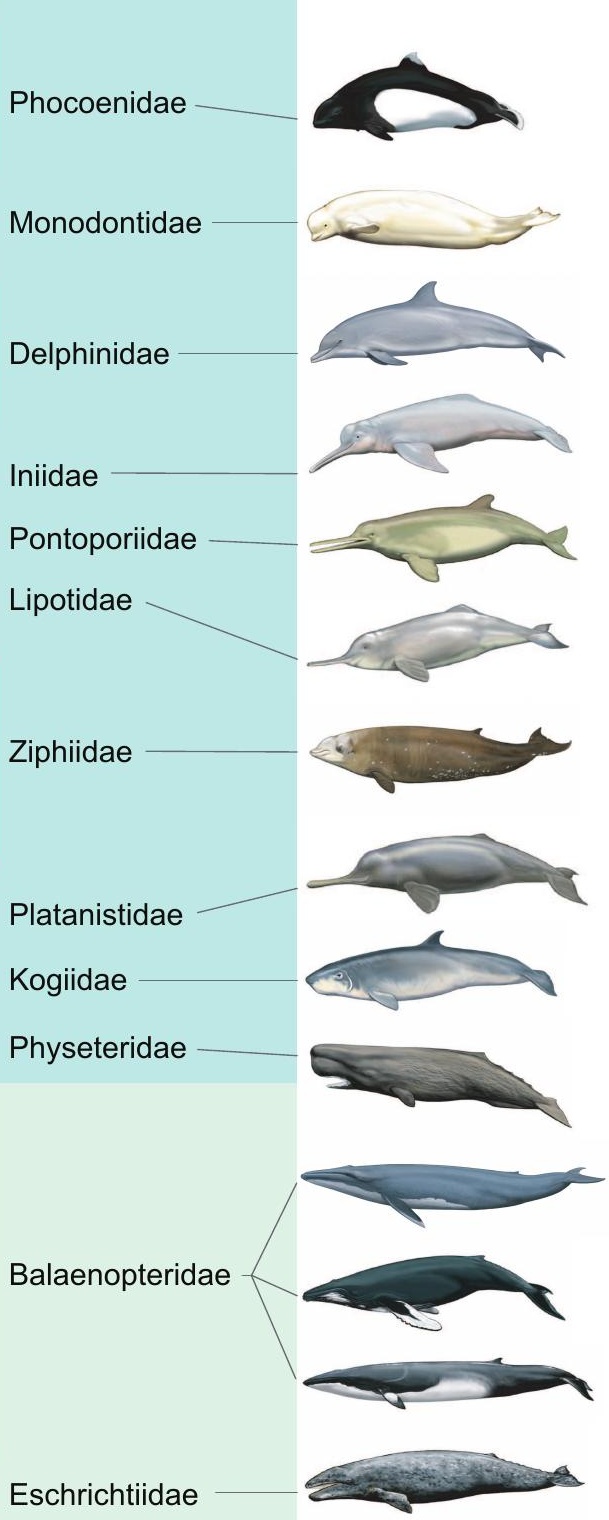

Eschrichtiidae

Neobalaenidae

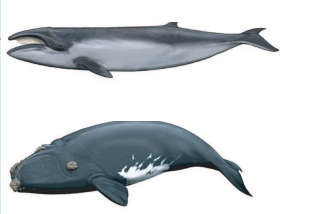

Balaenidae

\section{Mysticeti}


Table 1. Akaike Information Criterion (AIC) comparison of different codon frequency models in codeml.

\begin{tabular}{|c|c|c|c|c|c|}
\hline $\begin{array}{c}\text { Codon } \\
\text { frequency }^{\mathrm{A}}\end{array}$ & $\mathrm{K}$ & $\mathrm{AIC}^{\mathrm{B}}$ & $\Delta$ AIC & $\begin{array}{c}\text { Relative } \\
\text { weight }^{\mathrm{C}}\end{array}$ & $\begin{array}{c}\text { Normalized } \\
\text { relative } \\
\text { likelihood }\end{array}$ \\
\hline CF0 & 0 & 7155.407 & -75.28 & $4.50 \times 10^{-17}$ & $\sim 0$ \\
\hline CF1 & 3 & 7080.127 & 0 & 1.0 & 0.9996 \\
\hline CF2 & 9 & 7095.995 & -15.87 & $3.58 \times 10^{-4}$ & 0.0004 \\
\hline CF3 & 60 & 7247.637 & -167.51 & $4.22 \times 10^{-37}$ & $\sim 0$ \\
\hline
\end{tabular}

${ }^{\mathrm{A}}$ Comparisons were performed with a one-ratio model for all branches.

${ }^{\mathrm{B}} \mathrm{AIC}=2 \mathrm{~K}-2$ (log-likelihood) where $\mathrm{K}$ is the number of free parameters.

${ }^{\mathrm{C}}$ Relative weight $=\exp ^{0.5^{*} \Delta \mathrm{AIC}}$

Abbreviations, $\mathrm{CF} 0=$ frequencies for each codon are assumed to be equal; $\mathrm{CF} 1=$ codon frequencies are calculated from average nucleotide frequencies; $\mathrm{CF} 2=$ codon frequencies are calculated from average nucleotide frequencies at each of three codon positions; CF3 $=$ codon frequencies are treated as free parameters. 
Table 2. Lengths of protein-coding sequences (inclusive of stop codon) for placental species that have shorter or longer sequences than the 492-bp sequence length that occurs in most placental mammals.

\begin{tabular}{|l|l|}
\hline Taxon & Sequence length (bp) \\
\hline $\begin{array}{l}\text { Delphinidae (Globicephala } \\
\text { macrorhynchus, Orcinus orca, Tursiops } \\
\text { truncatus) }\end{array}$ & 477 \\
\hline Kogia sima & 480 \\
\hline $\begin{array}{l}\text { Hystricognathi (Cavia aperea, C. } \\
\text { porcellus, Fukomys damarensis, } \\
\text { Heterocephalus glaber, Octodon degus) }\end{array}$ & 489 \\
\hline Jaculus jaculus & 498 \\
\hline Ailuropoda melanoleuca & 537 \\
\hline
\end{tabular}


Table 3. Results of selection $(\mathrm{dN} / \mathrm{dS}=\omega)$ analyses with different branch models.

\begin{tabular}{|c|c|c|c|c|c|c|c|c|c|}
\hline Branch Model & log likelihood & $\omega 0$ & $\omega 1$ & $\omega 2$ & $\omega 3$ & $\omega 4$ & $\omega 5$ & $\omega 6$ & $\omega 7$ \\
\hline Model 1 ( $\omega 0$ : all branches) & -3537.0637 & 0.3427 & & & & & & & \\
\hline $\begin{array}{l}\text { Model } 2 \text { ( } \omega 0 \text { : background, } \omega 1 \text { : } \\
\text { stem and crown Odontoceti) }\end{array}$ & -3517.3990 & 0.2310 & 0.8095 & & & & & & \\
\hline $\begin{array}{l}\text { Model } 3(\omega 0 \text { : background, } \omega 1 \text { : } \\
\text { stem Cetacea + stem and crown } \\
\text { Odontoceti, } \omega 2 \text { : stem and crown } \\
\text { Mysticeti) }\end{array}$ & -3517.7231 & 0.2252 & 0.7734 & 0.2573 & & & & & \\
\hline $\begin{array}{l}\text { Model } 4(\omega 0 \text { : background, } \omega 1: \\
\text { stem and crown Odontoceti, } \omega 2^{\mathrm{B}} \text { : } \\
\text { stem Cetacea, } \omega 3 \text { : stem and crown } \\
\text { Mysticeti) }\end{array}$ & -3517.1093 & 0.2255 & 0.8095 & $\begin{array}{l}0.3648 \\
(6,4)\end{array}$ & 0.2573 & & & & \\
\hline $\begin{array}{l}\text { Model } 5 \text { ( } \omega 0 \text { : background, } \omega 1: \\
\text { stem and crown Odontoceti } \\
\text { without inactivating mutations; } \\
\omega 2 \text { : crown Odontoceti with } \\
\text { inactivating mutations) }\end{array}$ & -3517.3230 & 0.2310 & 0.7631 & 0.8772 & & & & & \\
\hline $\begin{array}{l}\text { Model } 6(\omega 0 \text { : background, } \omega 1 \text { : } \\
\text { stem and crown Odontoceti fixed } \\
\text { at } 1.0)\end{array}$ & -3518.0920 & 0.2311 & 1.0000 & & & & & & \\
\hline $\begin{array}{l}\text { Model } 7(\omega 0 \text { : background, } \omega 1 \text { : } \\
\text { stem and crown Odontoceti } \\
\text { without inactivating mutations, } \\
\omega 2^{\mathrm{B}}: \text { Phocoena } \omega 3^{\mathrm{B}}: \text { Physeter, } \\
\omega 4^{\mathrm{B}}: \text { Inia, } \omega 5^{\mathrm{B}}: \text { Pontoporia, } \omega 6^{\mathrm{B}} \text { : } \\
\text { Lipotes, } \omega 7^{\mathrm{B}}: \text { Platanista }\end{array}$ & -3510.2459 & 0.2310 & 0.7630 & $\begin{array}{l}999.0 \\
(1,0)\end{array}$ & $\begin{array}{l}2.6198 \\
(9,1)\end{array}$ & $\begin{array}{l}0.9221 \\
(17,4)\end{array}$ & $\begin{array}{l}2.8068 \\
(10,1)\end{array}$ & $\begin{array}{l}2.0006 \\
(13,2)\end{array}$ & $\begin{array}{l}0.1752 \\
(6,9)\end{array}$ \\
\hline
\end{tabular}

Model 1 Versus Model 2: 2 x $\Delta \operatorname{lnL}=39.9088, \mathrm{df}=1, \mathrm{p}=3.58 \times 10^{-10}$ (significant at $<0.000$ after Holm-Bonferroni correction). 
Model 2 Versus Model 4: 2 x $\Delta \operatorname{lnL}=0.5794, \mathrm{df}=2, \mathrm{p}=0.7485$

Model 2 Versus Model 5: 2 x $\Delta \operatorname{lnL}=0.1520, \mathrm{df}=1, \mathrm{p}=0.6966$.

Model 2 Versus Model $6^{\mathrm{C}}: 2 \mathrm{x} \Delta \ln \mathrm{L}=0.072, \mathrm{df}=1, \mathrm{p}=0.7884$

Model 2 Versus Model 7: 2 x $\Delta \operatorname{lnL}=14.3062, \mathrm{df}=6, \mathrm{p}=0.0264$ (not significant $[\mathrm{p}=0.106]$ after Holm-Bonferroni correction).

${ }^{\mathrm{A}}$ Model 3 is not nested with other models and log likelihood ratio tests were not performed.

${ }^{\mathrm{B}}$ Numbers in parentheses refer to the numbers of nonsynonymous and synonymous substitutions, respectively, estimated from ancestral state reconstructions with codeml after excluding all changes that are associated with gaps or ambiguous nucleotides for the relevant ancestral and descendant nodes.

${ }^{\mathrm{C}}$ The null distribution for the comparison between Model 2 and Model 6 is a 50:50 mixture of point mass 0 and $\chi^{2}$ with one degree of freedom. This distribution yields critical values of 2.71 at 5\% and 5.41 at 1\%. However, we followed Yang's (2007) advice and calculated $p$ values with $\chi^{2}$ and one degree of freedom (i.e., no 50:50 mixture) to guard against possible violations of model assumptions. 
Table 4. Akaike Information Criterion (AIC) comparison of different $\mathrm{dN} / \mathrm{dS}$ branch models in codeml.

\begin{tabular}{|c|c|c|c|c|c|}
\hline Branch model $^{\mathrm{A}}$ & $\begin{array}{l}\text { Number of } \\
\text { free } \\
\text { parameters }{ }^{B}\end{array}$ & $\mathrm{AIC}^{\mathrm{C}}$ & $\Delta \mathrm{AIC}$ & $\begin{array}{c}\text { Relative } \\
\text { likelihood }^{\mathrm{D}}\end{array}$ & $\begin{array}{l}\text { Normalized } \\
\text { relative } \\
\text { likelihood }\end{array}$ \\
\hline Model 1 ( $\omega 0:$ all branches $)$ & 0 & 7074.1274 & -39.6356 & $2.473 \times 10^{-09}$ & $1.421 \times 10^{-09}$ \\
\hline Model 2 ( $\omega 0$ : background, $\omega 1$ : stem and crown Odontoceti) & 1 & 7036.7980 & -2.3062 & 0.3157 & 0.1814 \\
\hline $\begin{array}{l}\text { Model } 3 \text { ( } \omega 0 \text { : background, } \omega 1: \text { stem Cetacea }+ \text { stem and } \\
\text { crown Odontoceti, } \omega 2: \text { stem and crown Mysticeti) }\end{array}$ & 2 & 7039.4462 & -4.9544 & 0.0840 & 0.0483 \\
\hline $\begin{array}{l}\text { Model } 4 \text { ( } \omega 0 \text { : background, } \omega 1 \text { : stem and crown Odontoceti, } \\
\omega 2 \text { : stem Cetacea, } \omega 3 \text { : stem and crown Mysticeti) }\end{array}$ & 3 & 7040.2186 & -5.7268 & 0.0571 & 0.0328 \\
\hline $\begin{array}{l}\text { Model } 5 \text { ( } \omega 0 \text { : background, } \omega 1: \text { stem and crown Odontoceti } \\
\text { without inactivating mutations, } \omega 2: \text { stem and crown } \\
\text { Odontoceti with inactivating mutations) }\end{array}$ & 2 & 7038.6460 & -4.1542 & 0.1253 & 0.0720 \\
\hline $\begin{array}{l}\text { Model } 6(\omega 0 \text { : background, } \omega 1 \text { : stem and crown Odontoceti } \\
\text { fixed at } 1.0)\end{array}$ & 1 & 7038.1840 & -3.6922 & 0.1579 & 0.0907 \\
\hline $\begin{array}{l}\text { Model } 7 \text { ( } \omega 0 \text { : background, } \omega 1 \text { : stem and crown Odontoceti } \\
\text { without inactivating mutations, } \omega 2-\omega 7 \text { : individual } \\
\text { odontocete branches with inactivating mutations) }\end{array}$ & 7 & 7034.4918 & 0 & 1 & 0.5748 \\
\hline
\end{tabular}

${ }^{\mathrm{A}}$ All comparisons were performed with codon frequency model 1 (CF1) results from PAML.

${ }^{\mathrm{B}}$ Relative to Model 1.

${ }^{\mathrm{C}} \mathrm{AIC}=2 \mathrm{~K}-2(\log$-likelihood $)$ where $\mathrm{K}$ is the number of free parameters.

${ }^{\mathrm{D}}$ Relative likelihood $=\exp ^{0.5 * \Delta \mathrm{AIC}}$ 
Table 5. Comparison of selection analyses for $O M P, C N G A 2$, and $C N G A 4$ with four branch categories. ${ }^{\mathrm{A}}$ For each gene, $\mathrm{dN} / \mathrm{dS}(=\omega)$ is shown for each branch category.

\begin{tabular}{|l|l|l|l|}
\hline Branch Category & OMP & CNGA2 & CNGA4 \\
\hline 1. Background & 0.2255 & 0.1120 & 0.1190 \\
\hline 2. Stem Cetacea & 0.3648 & 0.3023 & 0.3420 \\
\hline $\begin{array}{l}\text { 3. Stem and crown } \\
\text { Mysticeti }\end{array}$ & 0.2573 & 0.6047 & 0.3342 \\
\hline $\begin{array}{l}\text { 4. Stem and crown } \\
\text { Odontoceti }\end{array}$ & $0.8095^{\mathrm{B}}$ & $1.1907^{\mathrm{B}}$ & $1.4490^{\mathrm{B}}$ \\
\hline
\end{tabular}

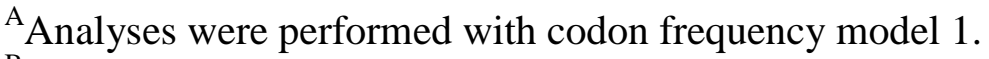

${ }^{\mathrm{B}}$ Not significantly different from $\omega=1.0$. 


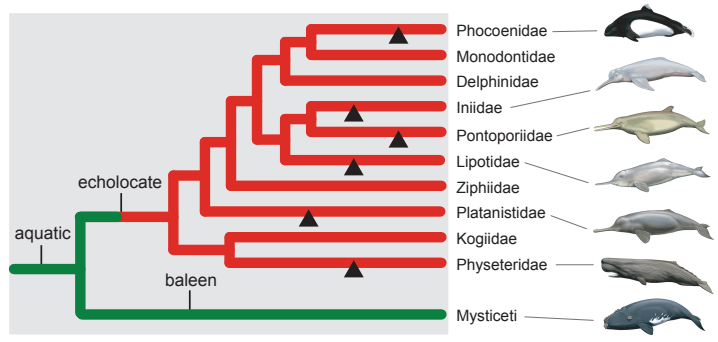

